\title{
Impact of Nutrition Education on Nutritional Status and Daily Dietary Pattern of College Going Girls
}

\author{
Joglekar, A. ${ }^{1}$, Bhoi, S. $^{2}$ \\ ${ }^{1}$ Professor, Govt. D.B. Girls' P.G. College, Raipur, Chhattisgarh, India \\ ${ }^{2}$ Government D.B. Girls' P.G. College, Raipur, Chhattisgarh, India
}

\begin{abstract}
Background: Vegetables and fruits are major dietary sources of fibers, vitamins, minerals and antioxidants. Its importance in nutrition and health is well established. Vegetables and fruits are major part of our food plate, although it has been observed that the dietary pattern of people has shifted from traditional food pattern to modern life style. The daily consumption of fruits and vegetables reduced to certain level which attributes the risk of life style diseases like cardiovascular, diabetes and anaemia. Approximately --\% population consume fruits and vegetables in daily diet. To conquer optimal health became a necessity of young population. Several studies confirms that more than $57.5 \%$ girls in India are suffering from major health problems like anemia, CVD, low immunity power and low physical fitness due to wrong dietary pattern, malnutrition, unhygienic environment and lack of knowledge about nutrition. Objectives: The present study was aimed to assess the impact of nutrition education on daily dietary pattern and nutritional status of college going girls. Methodology: A cross sectional study, using food frequency questionnaire and anthropometry measurements was carried out to elicit the data. 200 college going girls (100 as experimental and100 as control group) were purposively selected from the hostel. Nutritional status and daily dietary pattern of the samples was evaluated by using anthropometric indices height, weight, BMI, diet survey during pre and post intervention period. Results: Overall findings reveals positive impact of nutrition education on nutritional status of college going girls. We found positive relationship between existing nutrition knowledge and nutrition education on dietary habits of college going girls.
\end{abstract}

Keywords: College going girls, nutritional status, BMI, nutrition education

\section{Introduction}

College going age is the stages of completion of growth and sexual maturation. The timing of growth spurt and onset of sexual function varies in individual, which causes unhappiness and embarrassment among them. This wide individual range gives some vagueness in setting age borders to college going girls. Positive health of this segment is essential for proper development of country. In India 15\% population consist young people, having their studies in higher institutes, but the health status of this segment is alarming in term of deficiency disease by which they are suffering. In India 57.5\% girls are suffering from major nutritional problems like anemia, CVD, low immunity power and low physical fitness. Proper nutrition in this period can work as a pillar for a lifelong good health.

Nutritional anaemia mainly caused due to absence of important nutrients in diets, which involved in haemoglobin formation and poor absorption of important nutrients by the body. Several studied have investigated nutritional status of college going girls in different parts of India and confirmed that poor dietary practices and lack of knowledge about nutrition are major factors responsible for malnutrition among young population (.N. Arlappa et al.2015), (A. saibaba 2002) and (P.V. Kotecha et al. 2009).

Physical activity is an important part of daily life. It is more important for college going girls for maintaining a healthy weight. A physical activity builds and maintains healthy bones and muscles. Regular activity also helps to promote a healthy body. It has been observed that the due to change in life style pattern young population are facing several health problems like obesity, anaemia and even Vitamin-D deficiency. So nutrition education and health awareness about importance of balanced diet is needed in this period, to maintain the health (Recep Kurkcu and Sanliurfa-Turkey 2010).

Govt. has initiated several health policies with nongovernment agencies to combat health issues of this segment, but these policies are not yet properly implemented in urban and rural areas of country (Leonie Nzefa Dapi, 2005). Polices and initiated strategies for the well-being of college going girls can be successful only with publicprivate participation.

Vegetables and fruits are major part of our food plate, although it has been observed that the dietary pattern of people has shifted from traditional food pattern to modern life style. The daily consumption of fruits and vegetables reduced to certain level which attributes the risk of life style diseases like cardiovascular, diabetes and anaemia. The concepts in the field of nutrition are expanding and emphasizing on the use of fruits and vegetables to improve health and reduce the risk of diseases. It has been well established through researches that food acts as a remedy for several diseases like obesity, diabetes, cardio diseases and cancer etc. (James F. Sallis, Thomas L.1997). The present study was aimed to assess the impact of nutrition education on daily dietary pattern and nutritional status of college going girls.

\section{Methodology}

This study was conducted in Raipur city of Chhattisgarh. 200 college going girls pursuing under graduated and post graduated programs were selected for the study. As a first step of investigation personal information about age, cast , type of family, birth order, no. of family members 


\section{International Journal of Science and Research (IJSR) \\ ISSN (Online): 2319-7064}

Index Copernicus Value (2013): 6.14 | Impact Factor (2015): 6.391

,educational status of parents, occupation of parents, monthly income of parents, type of house were collected as demographic profile. To maintain study protocol the proposed work was approved by institutional ethical committee.

A pilot study was performed on five percent of the selected sample as suggested by Kothari (2005) before the final conduction of the survey.

Girls were divided into two groups one with controlled group (100) whose $\mathrm{Hb}$ was normal and second as experimental group $(n=100)$ whose $\mathrm{Hb}$ was less than normal $(11 \mathrm{gm} / \mathrm{dl})$.

Assessment of nutritional status is one the first step in the formulation of any public health strategy to combat malnutrition, as the ultimate of nutritional assessments is to improve human health Mahtab S. Bamji, N. Pralhad Rao, Vinodini Reddy (1998). So Height in (c. m.), weight in (k.g.), were taken to get BMI for the assessments of nutritional status. The importance of these measurements are well established by (Elizabeth, 2000), (Ramalingaswami, 1993) and (Priyatomako et al., 2001). The BMI (body mass index) (Quetlet index) was calculated by dividing the individual's weight (kilogram) by the square of height (meters). After the computation of BMI, subjects were classified according to the norms given by Mahtab $\mathbf{S}$. Bamji, N. Pralhad Rao, Vinodini Reddy (1998).

$\mathrm{BMI}=$

$\frac{\text { Weight }(\mathrm{kg})}{\text { Height }^{2}(\mathrm{M})}$

Dietary pattern of individual was collected through the interview and 3 days recall method. All the results were statistically analyzed using SPSS software (version16).

\section{Results and Discussion}

\section{Demographic profile}

Demographic profile gives clear picture of family's culture and customs. Total 10 variables were obtained from the background information (Table No-1). Out of 200 girls $65 \%$ girls were between the age group of 18-20 years of age. $20 \%$ girls were between the ages of 21-23 years and only $15 \%$ girls were between the age group of 24-26 years respectively. While gathering data of educational status of adolescent's girls, it was observed that $83 \%$ girls were under -graduate and $17 \%$ girl was post graduate student. Birth orders of as per affect the health status, so it was collected cautiously. Out of 200 girls $50 \%$ girls had birth order between $1-2,25 \%$ girls were between the $3-4$ and $25 \%$ girls were between the 5-6 numbers of birth order.

The educational qualification of a family reflects the clear picture of existing knowledge and importance of nutrition in their life. It was observed that $60 \%$ fathers were higher secondary educated, $25 \%$ fathers were graduate and only $15 \%$ were post graduate while analyzing mother's education $35 \%$ mothers were high school pass, $30 \%$ were higher secondary, $25 \%$ were appeared in college and only $10 \%$ mothers were post graduate. $63 \%$ girls were found living in kachha house and $37 \%$ girls were living in pakka house.

While analyzing family it was observed that $40 \%$ girls were having 5-10 family members and 60\% girls were having 11 20 family members. Out of 200 college girls were $60 \%$ living in joint family and $40 \%$ girls were living in nuclear family in present study.

The monthly income of girl's family was noted, it shows that out of 200 parents, income of $20 \%$ parents had income $<5000$ Rs. ,20\% parents had income between the 5000-9999 Rs., $10 \%$ parents were between the 10000-14999 Rs., $20 \%$ were 15000-24,999 Rs. and 30\% parents were between the $25,000-50,000$ Rs. The category of cut was the last variable obtained in presents study $50 \%$ girls were belonging to general category, $25 \%$ girls were belonging to other beck warred classes (OBC) and $12.5 \%$ girls were SC \& $12.5 \%$ Were ST category.

While analyzing BMI categories of experimental group, it was observed that the mean BMI levels were increased by 20.70 to 21.34 . While categorizing girls as per their grades of obesity it was noticed that $58 \%$ girls were normal, $23 \%$ were under weight, $13 \%$ were overweight and only $6 \%$ had obesity. It can be concluded that there was a positive impact of nutrition education on nutritional status of college going girls, as $87 \%$ girls were shifted from various grades of BMI to normal BMI (Table No.2).

Table No-3 depicts the comparative analysis of pre and post mean score of BMI, of 200 college going girls. It was observed that BMI levels were increased from 20.70 to 21.34 in experimental group and in control group it was increased by 23.87 to 24.33 . The results were significant at $.01 *$ level (Table No.3).

While analyzing nutrient intake percent of adequacy of college going girls, it was observed that in experimental group the nutrient intake was enhanced after nutrition education as final data for percents of adequacy of total calorie found excess +102.24 ,carbohydrate was enhanced by +101.89 and fat +107.32 .The consumption of protein was found to be in deficit when compared against the suggested allowance (RDA 2010) (Figure No.1)

Consumption of cereals, milk and milk products and fats and oils, sugar and sugar products were found to be excess and the percentage adequacy of these food stuffs included +129.9 per cent, +133.3 per cent and +175 per cent respectively (Table No-4).

The consumption of pulses, green leafy vegetables, other vegetables, root vegetables calcium, iron and fruits were found to be in deficit.When compared against the suggested allowance given by RDA (2010) and the percentage inadequacy of pulses, green leafy vegetables, other vegetables and fruits were -66.6 percent, -11.33 percent, -37.5 percent, -75 percent, -83.3 percent,-71.4 percent and 17.5percent respectively . 


\section{International Journal of Science and Research (IJSR) \\ ISSN (Online): 2319-7064}

Index Copernicus Value (2013): 6.14 | Impact Factor (2015): 6.391

\section{Discussion}

There are no previous studies that characterize the impact of nutrition education on nutritional status of college going girls. To the best of our knowledge, this is the first study based on evaluation of nutrition intervention on nutritional status of college going girls from Raipur city. The college going girls are very important segment of society in terms of vulnerability who did not give proper attention towards their nutritional needs.

The data on demographic profile and dietary survey of girls were comparable with other studies conducted in India for the assessment of nutritional status of college going girls. The overall result of present study shows that after nutrition education $87 \%$ girls fall in normal BMI category, the results were close to the study conducted by A. saibaba (2002) and varun gaikli et al. (2014).

The consumption of food stuff of $42 \%$ college going girls was changed after nutrition education. The present result support other previous study results Leonie et al. (2005)who worked on adolescents food habits and nutritional status in urban and rural areas in Cameroon, Africa.

The present study and data on prevalence of anaemia and impact of nutrition education on nutritional status of college going girls can be recognized as mile stone in the field of nutrition. Public private partnership and parent's role can improve the nutritional status of girls.

\section{Conclusion}

Based on the above results it can be concluded that addition of fruits and vegetables in daily diet can increase the nutritional adequacy of other nutrients which will definitely enhance the nutritional status of population. Further studies based on nutrition education particularly promoting indigenous foods are required on other segment of population to improve their fitness.

\section{References}

[1] A.Saibaba, M. Mohan ram, G. v. Raman Rao,Uma Devi,.T.S. Syamala (2002). Nutritional status adolescent's girls of urban slums and the impact of IEC on their nutrition knowledge and practices. Indian journal of community medicine, vol.xxvii, 4, 151-155.

[2] A.Mahtab S. Bamji, N. Pralhad Rao, Vinodini Reddy (1998). Textbook of Human Nutrition. Oxford and IBH Publication Cooperative Privet Limited, Calcutta, New Delhi.

[3] A.Report of the Expert Group of the Indian Medical Research (2010). Nutrition Requirements and Recommended dietary Allowances for Indians .Indian Council of Medical Research (ICMR). New Delhi .

[4] Brahmam,G.N,V., Laxmaiah,A., Mallikharjuna,K. and Reddy,G.(2005) Methodology of assessment of diet and nutritional status of community. In Manual of National Institute of Nutrition, Hyderabad, pp.7-9, 13, 16.
[5] Elizabeth, K.E.(2000)Measurements techniques. In Fundamental of Pediatrics , First Edn, Aras Publ., Hyderabad, Pp.50-69.

[6] James F. Sallis, Thomas L. McKenzie, John E. Alcaraz, Bohdon Kolody, Nell Faucette ,Melbourne F. Hovell, (1997). The effects of a 2 -Years physical education program (SPARK) on physical activity and fitness in elementary school students. American journal of public health, Vol. 87, pp. 1328-1330.

[7] Leonie Nzefa Dapi, Christophe Nouedoui, urban Janlert , lena haglin ( 2005).Adolescents food habits and nutritional status in urban and rural areas in Cameroon, Africa . Scandinavian journal of nutrition, Vol. 49(4), pp. 151-158.

[8] N.Arlappa, N. Balakrishna, A. Laxmaiah, GNV Brahman (2012). Prevalence of a anaemia among rural pre-school children of Maharashtra, India. Indian journal of community health, vol.24, no.1, 4-8.

[9] Priyatomako,D.,Strauss,B.J.G. and Wahlquest,M.L.(2001)Energy adaptation and obesity Scientific Progress and Abstract, XXII Annual conference of Indian Dietetic Association,NIN,p.168.

[10] P.V. Kotecha, S. Nirupam and P.D. Karkar (2009). Adolescent girl's anaemia control programme, Gujarat, India. Indian journal medical researches 130, pp584589.

[11] Ramalingaswami, V.(1993) New global perspective in overcoming malnutrition XV International congress of Nutrition, Adeliade, Australia.

[12] Recep Kurkcu and Sanliurfa-Turkey (2010). The effects of short - term exercise on the parameters of oxidant and antioxidant system in handball players. African journal of pharmacy and pharmacology, Vol. 4 (7), pp. 448-452.

[13] S. Mahtab Bamji, N. Pralhad Rao, Vinodini Reddy (1996).Texbook of human nutrition ,Oxford and IBH publication Co. PVI.LID. 